\title{
Magnetic field effect on exciplex-forming organic acceptor/donor system: a powerful tool for understanding the preferential solvation
}

\section{- Hoang Minh Hao}

University of Technology and Education, Ho Chi Minh City

- Pham Thi Bich Van

Nong Lam University, Ho Chi Minh City

\section{ABSTRACT}

Many acceptor/donor systems can form excited-state charge-transfer complexes (exciplexes) in photo-induced electron transfer reactions. Exciplex can be detected by their luminescence. In addition, the exciplex luminescence is magneto-sensitive. Here, we employ an approach based on the magnetic field effect on the exciplex of 9,10dimethylanthracene/ $N, N$-dimethylaniline pair in micro-homogeneous and micro-heterogeneous binary solvents to investigate the effects of the preferential solvation processes on solute molecules in solutions. Micro-homogeneous solvent mixtures of propyl acetate Key words: Exciplex, magnetic field effect, photo-induced electron transfer, radical ion pair

\section{INTRODUCTION}

Exciplexes, excited-state charge-transfer complexes, are formed in bimolecular photoinduced electron transfer (PET) reactions of excited electron acceptor $\left(\mathrm{A}^{*}\right)$ and electron donor (D) [1]. Fig. 1 depicts a scheme of the PET reaction in a typical exciplex forming acceptor/donor system. Here, the vertical axis refers to free energy and the abscissa expresses a reaction coordinate involving the distance between $A^{*}$ and $D[2,4]$. The exciplex is formed
$(P A) /$ butyronitrile $(B N)$ allow for a systematic variation of the static dielectric constants, $\varepsilon_{s}$, in the range from 6.0 to 24.6. The mixtures of toluene (TO)/dimethylsulfoxide (DMSO) with varying the $\varepsilon_{s}$ values in the range from 4.3 to 15.5 are used as micro-heterogeneous binary solvents. In micro-heterogeneous environment, DMSO molecules get preferentially favoured in the solvation shell, forming micro-clusters surrounding the solute molecules. This solvation effect is reflected in the altered magnetic field effects, lifetimes and dissociation rate constants of the exciplexes. when the contact distance of $\mathrm{A}^{*}$ and $\mathrm{D}$ is $6.5 \AA$ while the distance of $10 \AA$ refers to radical ion pair (RIP). In general, exciplexes can be monitored by their emission, which is spectrally well separated from the locally-excited emission of A* [5-7]. In addition, the exciplex population can react to a weak external magnetic field [2-4, $8-12]$. This effect originates from the so-called radical pair mechanism [13, 14]. 


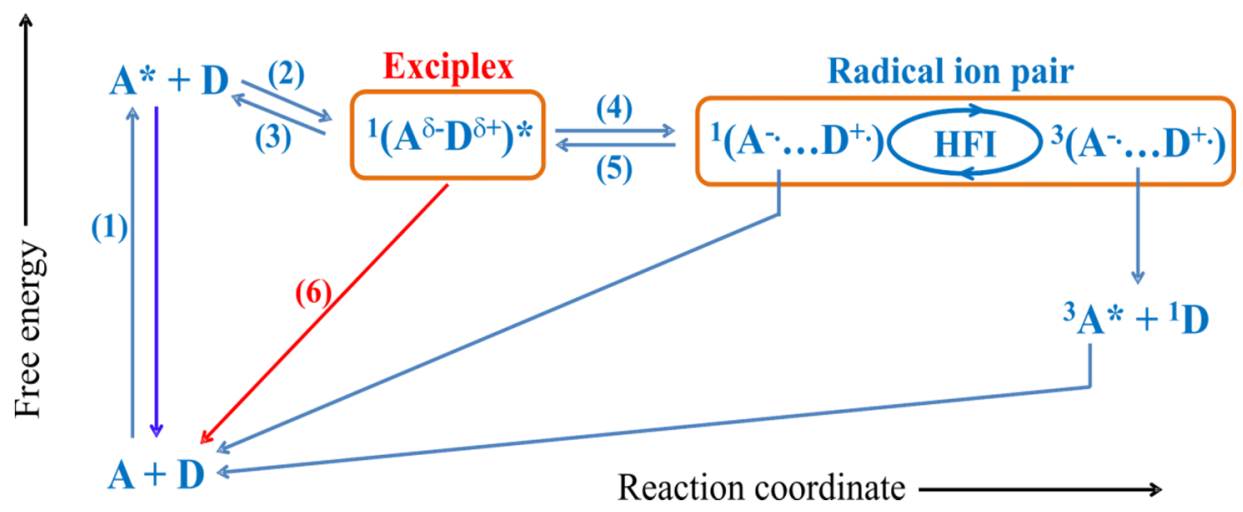

Fig. 1. Species and reactions involved in a photo-induced electron transfer reaction. Exciplex occurs as an intermediate in reaction. Photo-excitation (1), exciplex formation (2), exciplex dissociation into locally-excited acceptor (3), exciplex dissociation into radical ion pair-RIP (4), singlet-triplet conversion by hyperfine interaction (HFI), re-formation of the exciplex from the singlet RIP (5), exciplex emission (6). The blue and red arrows give the decay processes of either the locally-excited acceptor or the exciplex. $3 \mathrm{~A}^{*}$ denotes the triplet products.

Magnetic field effect (MFE) on exciplex results from the inter-conversion of the singlet and the three triplet states of the RIP in equilibrium with the exciplex. Fig. 2 depicts the effect of an external magnetic field on singlettriplet conversion according to the hyperfine coupling mechanism (HFC). Due to the Zeeman interaction, an external magnetic field will remove the degeneracy of the three triplet sublevels $\left(T_{0}\right.$ and $\left.T_{ \pm}\right)$of spin-correlated RIPs generated via photo-induced electron transfer in solution. When the energy separation between three triplet states exceeds the size of the mixing interaction, $\mathrm{T}_{ \pm}$cannot mix with the singlet state, $\mathrm{S}$. Thus, the external magnetic field reduces the probability of intersystem crossing and, therefore, changes the relative concentrations of both singlet and triplet states [14-17]. Due to reversibility of the singlet RIP and the exciplex, the change of the concentration of singlet RIP can be detected through the emission of the exciplex. In other words, the exciplex luminescence is also magneto sensitive. Note, that the spin mixing between $S$ and $T_{0}$ occurs when the electron exchange interaction, $J(r)$, depending exponentially on the distance between radical ions and the determination of the energy gap between the $\mathrm{S}$ and $\mathrm{T}_{0}$ levels is negligible [17].

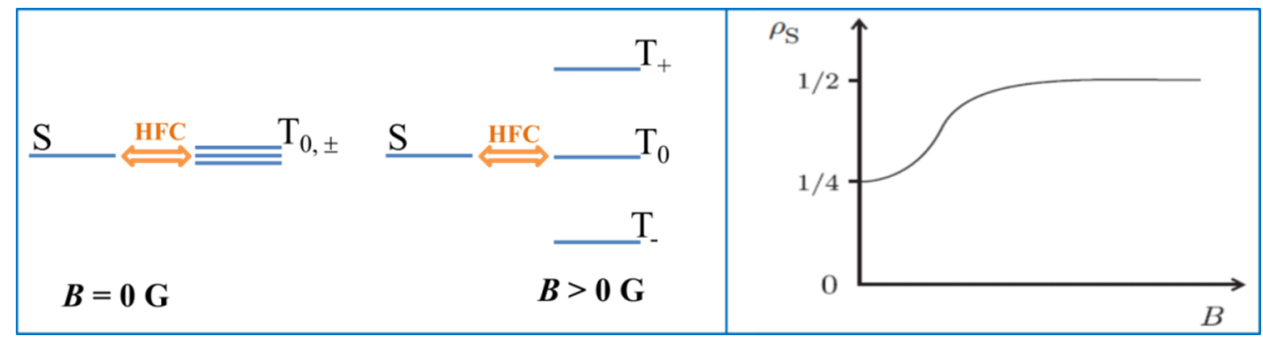

Fig. 2. Left panel refers to energy separations of singlet $(\mathrm{S})$ and three triplet $\left(\mathrm{T}_{0, \pm}\right)$ states in the absence and presence of an external magnetic field, $B$. The dependence of singlet RIP probability, $\rho_{\mathrm{S}}$, on the external magnetic field is shown in the right panel. Before reaching the saturating value, $\rho$ s increases with increasing the magnitude of $B$.

\section{Trang 66}


MFEs of the exciplexes strongly depend on solvent polarity [1-7]. In particular, the presence of polar micro-domains in binary solvents may affect the preferential solvation process of radical ion pairs (RIPs). This results in some interesting phenomena. The $B_{1 / 2}$ values (the field at which the delayed exciplex emission reaches half of its maximum intensity relative to that at zero field) show either a decrease in micro-heterogeneous solvents or remain constant in microhomogeneous solutions with increasing polarity [8]. These results demonstrated that any factors imposed on the RIP dynamics may affect on the MFE of the exciplex and this effect is a powerful tool to investigate the specific solvation processes.

The paper is structured as follows: In section 2 we show the apparatuses to measure the absorption and fluorescence spectra of acceptor/donor pair of 9,10dimethylanthracene/ $N, N$-dimethylaniline before the reader is fully acquainted with the preparations of micro-homogeneous (propyl acetate/butyronitrile) and micro-heterogeneous (toluene/dimethylsulfoxide) binary solvents with varying different static dielectric constants. The properties of solvent mixtures, e.g., viscosities $(\eta)$, static dielectric constants $\left(\varepsilon_{\mathrm{s}}\right)$ are shown in this part as well. Thereafter, we continue by presenting an experimental method to measure the MFEs on the exciplexes of 9,10dimethylanthracene/ $N, N$-dimethylaniline system based on steady-state measurements in microhomogeneous and micro-heterogeneous solutions. In section 3, we then show the solvent property dependence of MFEs $\left(\chi_{\mathrm{E}}\right)$, lifetimes $\left(\tau_{\mathrm{E}}\right)$ and dissociation rate constants $\left(k_{\mathrm{d}}\right)$ of the exciplexes, and a discussion of the effect of the preferential solvation of polar components in binary solvents on the $\chi_{\mathrm{E}}, \tau_{\mathrm{E}}$ and $k_{\mathrm{d}}$. Finally, we close with conclusions in section 4 .

\section{MATERIALS AND METHODS}

Absorption spectra of the studied systems are recorded on Shimadzu UV-3101-PC UV-VisNIR spectrophotometer. The fluorescence spectra are measured on a thermostatted Jobin Yvo Fluoromax-2 spectrofluorimeter, sampling time: $1 \mathrm{~s} \mathrm{~nm}^{-1}$. The temperature for fluorescence measurements is held $\mathrm{T}=295 \mathrm{~K}$ with the control of a Haake F3 thermostat. For MFE steady-state measurements, a detailed description of the experimental procedure and the apparatuses used is depicted in refs 2, 4. The concentration of donor is $0.06 \mathrm{M}$, while that of the acceptor is $2.10^{-5} \mathrm{M}$. Samples are prepared in septa-sealed quartz cuvettes with $1 \mathrm{~cm}$ path length. In order to remove dissolved oxygen, all solutions are sparged with nitrogen gas for 15 minutes prior to addition of the donor. The cuvette is immersed between two magnets. MFEs on exciplexes from steady-state measurements are recorded using a thermostated cell $(295 \mathrm{~K})$ coupled to a Jobin Yvon FluoroMax2 fluorescence spectrometer via light guides. The liquid donor is added directly through the septum using a Hamilton syringe. The exciplex lifetime, $\tau_{\mathrm{E}}$, is determined from the exciplex emission spectrum based on TimeCorrelated Single Photon-Counting (TCSPC) technique in the absence of a saturating external magnetic field. TCSPC apparatus is described in details in ref 2. The exciplex formation is efficient when the excited acceptor and donor can be positioned into a sandwich-like conformation [18]. Thus, we have studied the dependent MFE on the 9,10-dimethylanthracene (AcceptorA) $/ N, N$-dimethylaniline (Donor-D) system in binary solvents. Chemical structures of acceptor and donor are depicted in Fig. 3. 
<smiles>Cc1c2ccccc2c(C)c2ccccc12</smiles>

9,10-Dimethylanthracene (Acceptor-A)<smiles>CN(C)c1ccccc1</smiles>

$N, N$-Dimethylaniline (Donor-D)

Fig. 3. Chemical structures of acceptor and donor have been used in the present work

The solvent medium strongly affects on the magnetic field effect of the exciplex. Here, we have designed two binary solvents in terms of micro-homogeneity and micro-heterogeneity. Mixtures of propyl acetate (PA, $\varepsilon_{\mathrm{s}}=6.0, \eta=0.58$ $\mathrm{cP}) /$ butyronitrile $\left(\mathrm{BN}, \varepsilon_{\mathrm{s}}=24.6, \eta=0.58 \mathrm{cP}\right)$ varying the static dielectric constants, $\varepsilon_{s}$, in the range from 6 to 24.6 are selected as microhomogeneous binary solvents. The different $\varepsilon_{\mathrm{s}}$ values are prepared according to: $\varepsilon_{\mathrm{s}}\left(w_{1}\right)=w_{1} \varepsilon_{1}+$ $\left(1-w_{1}\right) \varepsilon_{2}$ with $\varepsilon_{1}$ and $w_{\mathrm{i}}$ denoting the dielectric constant and weight fraction of component $i$ [2]. In these mixtures, the viscosity ( $\eta=0.58 \mathrm{cP})$, and thus, the diffusion coefficients are nearly constant [4]. The refractive index $(n=1.383)$ is likewise almost invariant with solvent composition [2]. The Pekar factor $\left(1 / n^{2}-1 / \varepsilon_{s}\right)$ of PA/BN mixtures, which governs the outer-sphere electron transfer reorganization energy and, thus, the rate of ET processes, varies by only $\pm 5 \%$ in the studied $\varepsilon_{\mathrm{s}}$ range $[19,20]$.

The bulk dielectric constants, $\varepsilon_{s}$, of microheterogeneous toluene (TO, $\varepsilon_{\mathrm{s}}=2.4, \eta=0.55$
$\mathrm{cP}$ )/dimethylsulfoxide (DMSO, $\varepsilon_{\mathrm{s}}=50.0, \eta=2.2$ $\mathrm{cP}$ ) mixtures vary in the range from 4.3 to 15.5 via: $\quad \varepsilon_{\mathrm{s}}=62.5 \exp \left[-\left(1-x_{\mathrm{DMSO}}\right) / 0.78\right]-15.6$ with $x_{\text {DMSO }}$ giving the DMSO mole fraction in microheterogeneous mixture [8]. The solvent viscosity $\eta(\gamma)$ and Pekar factor $(\gamma)$ increase with increasing the DMSO concentration in TO/DMSO mixtures $[8,21]$. MFEs on exciplexes from steady-state measurements are recorded in the absence and presence of a saturating external magnetic field at 295 K. All fluorescence signals have been background corrected.

\section{RESULTS AND DISCUSSION}

Fig. 4 depicts the absorption and emission spectra of 9,10-dimethylanthracene (DMAnt) in the absence and presence of $N, N$-dimethylaniline (DMA). The acceptor is excited at $375 \mathrm{~nm}$ to be sure that the donor is not excited at excitation wavelength of the acceptor. The emission spectrum of acceptor is directly accessible from the spectrum in the absence of donor. A model is employed to extract the exciplex emission [22, 23].

\section{Trang 68}




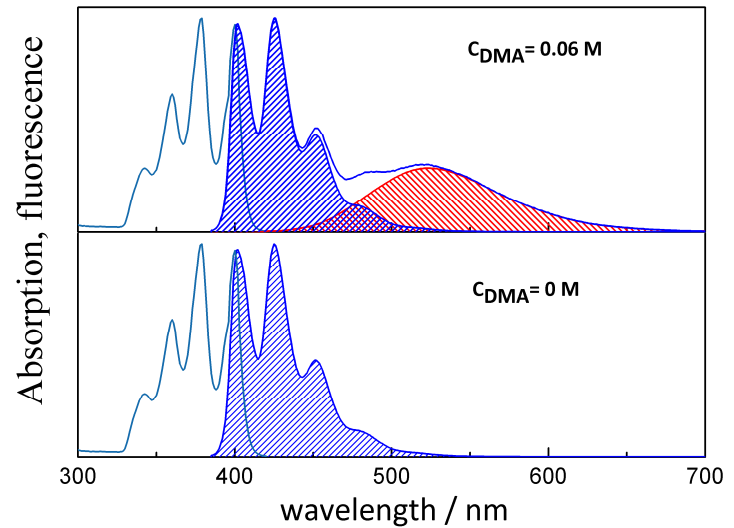

Fig. 4. Absorption and fluorescence spectra of 9,10-dimethylanthracene in the absence (bottom) and presence (top) of $N, N$-dimethylaniline $\left(\mathrm{CM}_{\mathrm{M}}=0.06 \mathrm{M}\right)$ in PA/BN mixture with a static dielectric constant of $\varepsilon_{\mathrm{s}}=12.0$. The fluorescences of the excited acceptor and the exciplex are shaded in blue and red, respectively.

As shown in Fig. 4, the emission spectrum of constant of $1 \mathrm{~s}$. At each time, three measurements the exciplex is separated from the fluorescence spectrum of the excited acceptor $A^{*}$. When applying a saturating external magnetic field $\left(B_{0}\right.$ $=62 \mathrm{mT})$, the emission intensity of the exciplex increases. Fig. 5 refers to the time-dependent MFE on the DMAnt/DMA exciplex emission in steady-state measurements. The exciplex emission is detected at $550 \mathrm{~nm}$ for $60 \mathrm{~s}$, time are accumulated, there by alternating zero $\left(B_{0}=0\right.$ $\mathrm{mT})$ and saturating magnetic field $\left(B_{0}=62 \mathrm{mT}\right)$. As noted above, an external magnetic field changes the relative populations of singlet and triplet RIPs. The singlet RIP population increases, and the exciplex is in equilibrium with the singlet RIP. This causes an increase of the exciplex population.

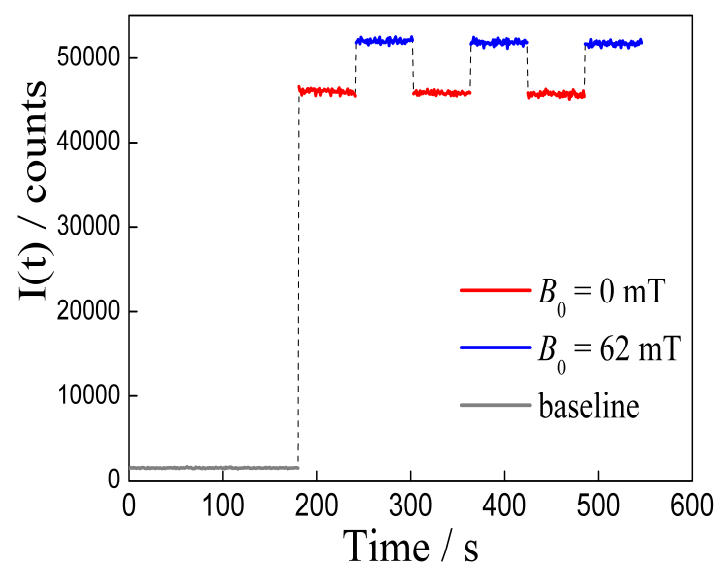

Fig. 5. Time-dependent magnetic field effect on the exciplex emission of the 9,10-dimethylanthracene/ $N, N$ dimethylaniline system from steady-state measurements in the absence and presence of an external magnetic field.

The exciplex emission is observed at $550 \mathrm{~nm}$. Mixture of TO/DMSO at $\varepsilon_{s}=11.5$ is used as solvent.

Time scans at the emission wavelength $\left(\lambda_{\mathrm{em}}=550 \mathrm{~nm}\right)$ of the exciplex are used to evaluate the MFE on the exciplex, $\chi \mathrm{E}$, given by:

$$
\chi_{E}=\frac{I\left(\lambda_{e m}, B_{0}=62 m T\right)-I\left(\lambda_{e m}, B_{0}=0 m T\right)}{I\left(\lambda_{e m}, B_{0}=0 m T\right)}
$$


Here, I $\left(\lambda_{\mathrm{em}}, B_{0}=62 \mathrm{mT}\right)$ and $\mathrm{I}\left(\lambda_{\mathrm{em}}, B_{0}=0\right.$ $\mathrm{mT})$ are the mean intensities of the exciplex at $\lambda_{\mathrm{em}}=550 \mathrm{~nm}$ in a saturating and in the absent magnetic field. All emission intensities are baseline extracted. Fig. 6 refers to the solvent dependence of the MFEs of the exciplexes of the DMAnt/DMA pair determined by eq 1 in microhomogeneous and micro-heterogeneous binary solvents.

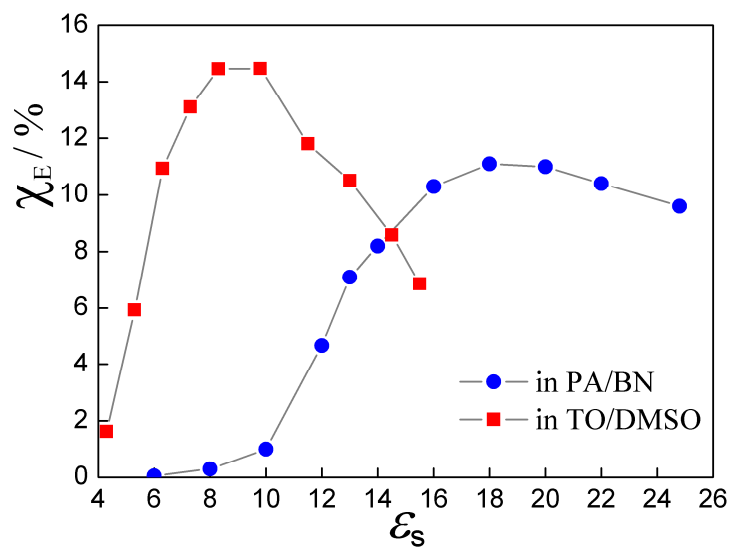

Fig. 6. Steady-state MFEs of the exciplexes $\left(\chi_{\mathrm{E}}\right)$ in PA/BN (blue circles) and TO/DMSO (red circles) mixtures with varying the dielectric constants, $\varepsilon_{s}$.

MFE features have been analyzed in terms of $\varepsilon_{\mathrm{s}}$, onset, $\varepsilon_{\mathrm{s}, \max }\left(\varepsilon_{\mathrm{s}}\right.$ values showing the onset and maximum of MFEs, respectively), xonset, xmax (mole fraction values of polar component in binary solvent showing the onset and maximum of MFEs) and $\chi_{\max }$ (the maximum MFE obtained). Table 1 gives the above parameters in two binary solvents. The onset and maximum of MFEs obtain at smaller $\varepsilon s$ values in TO/DMSO mixtures. The maximum MFE value $\left(\chi_{\max }=\right.$ $14.6 \%$ appears at $\varepsilon_{\mathrm{s}}=8.3$ in micro- heterogeneous solutions while that obtains at $\varepsilon_{\mathrm{s}}=$ $18\left(\chi_{\max }=11.4 \%\right)$ in micro-homogeneous ones. As mentioned above, RIP dynamics may reflect altered MFEs. The environment around RIP changes with the change in the composition of the solvent mixtures. According to suppan's model, the polar micro-domains (DMSO or BN) around solute species (RIP or exciplex) are produced via ion-dipole and dipole-dipole interactions of solute molecules with the polar components $[24,25]$.

Table 1. The parameters used to analyse the MFEs of the DMAnt/DMA exciplexes in microhomogeneous and micro-heterogeneous binary solvents

\begin{tabular}{|l|l|l|l|l|l|}
\hline Solvent & $\varepsilon_{s, \text { onset }}$ & $x_{\text {onset }}$ & $\varepsilon_{s, \max }$ & $x_{\max }$ & $\chi_{\max }(\%)$ \\
\hline $\mathrm{PA} / \mathrm{BN}$ & 8.0 & 0.15 & 18.0 & 0.72 & 11.4 \\
\hline TO/DMSO & 4.3 & 0.10 & 8.3 & 0.25 & 14.6 \\
\hline
\end{tabular}

\section{Trang 70}


In micro-heterogeneous environment, DMSO molecules get preferentially favoured in the solvation shell, forming micro-clusters surrounding the RIPs [25-30]. The results have been published in ref 8 , the authors used the dielectric continuum model suggested by Basilevsky et al [31] to simulate the local concentration of DMSO, $y(r)$, surrounding RIP in TO/DMSO mixtures $(r$ is inter-radical separation). The polar micro-domains are surrounding radical ions and the space in between two radical ions. Irrespective of DMSO mole fraction in mixtures, the ions are covered by a layer of DMSO with a local DMSO concentration, $y(r)=1$. This solvation effects on RIP lifetimes and induces an effective compromise between separation and recombination in geminate RIPs [8]. Thus, MFEs appear and reach the maximum value at smaller $\varepsilon_{\mathrm{s}}$ in TO/DMSO solutions.

After reaching the maximum value, MFEs decrease with increasing the solvent polarity. The effect of solvent polar components reaches saturation with increasing their mole fraction in mixture. At high $\varepsilon_{\mathrm{s}}$ values, i.e., high mole fractions of $\mathrm{BN}$ and DMSO in the corresponding mixtures, the separation of the two radicals in RIP is favourable, but the radical reencounter probability in the geminate cage is not sufficient due to the prevention from solvent polar components (BN or DMSO) in solution. This results in a decrease in MFEs.

The dependence of the exciplex lifetime, $\tau_{\mathrm{E}}$, on solvent polarity is depicted in Fig 7. The exciplexes exponentially decay. Their lifetimes are obtained by fitting a combination of exponential functions to the experimental TCSPC measurements [2]. The exciplex lifetimes decrease with increasing the mole fractions of BN or DMSO in micro-homogeneous and microheterogeneous solutions. These results can be explained by the effect of the environment around the exciplex. The local BN or DMSO concentrations increase with increasing their mole fractions in mixtures. The micro-cluster formation of polar molecules surrounding the charge-transfer dipoles (exciplexes) governs the exciplex lifetime. As mentioned above, the exciplex is formed in a contact distance between excited acceptor $\left(\mathrm{A}^{*}\right)$ and donor (D). The dipoledipole interaction increases with increasing the BN or DMSO concentrations in solvation shell surrounding exciplexes. This causes the exciplex to dissociate into RIPs, i.e., the exciplex lifetime decreases.

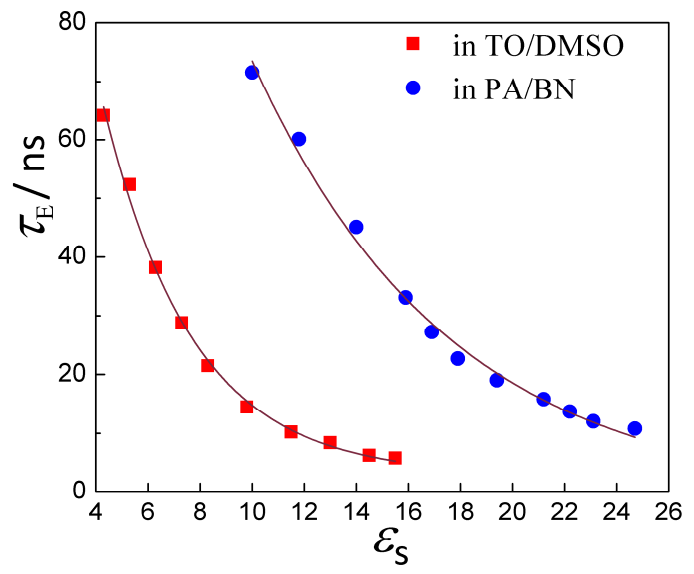

Fig. 7. Solvent polarity dependence of the exciplex lifetimes of the DMAnt/DMA system in PA/BN (blue circles) and TO/DMSO (red squares) mixtures 
The exciplex kinetics is evaluated through the rate of exciplex dissociation, $k_{\mathrm{d}}$, into RIP (pathway 4 in Fig. 1). The $k_{\mathrm{d}}$ values are extracted by least-squares fitting to time-resolved MFE data of the exciplex [2, 4]. The time-resolved MFEs of exciplexes are measured based on TCSPC technique in the absence and presence of a saturating external magnetic field $[2,4]$. The plot of $k_{\mathrm{d}}$ as a function of solvent polarity is described in Fig. 8. The $k_{\mathrm{d}}$ increases with increasing the solvent polarity, i.e., the exciplexes dissociate into RIPs faster. The enrichment of polar components (BN or DMSO) in solvation shell surrounding solute exciplex mainly governs the separation of the exciplex into the ions. That is reflected in the trend of $\mathrm{kd}$ with increasing the mole fractions of polar components in solvent mixtures.

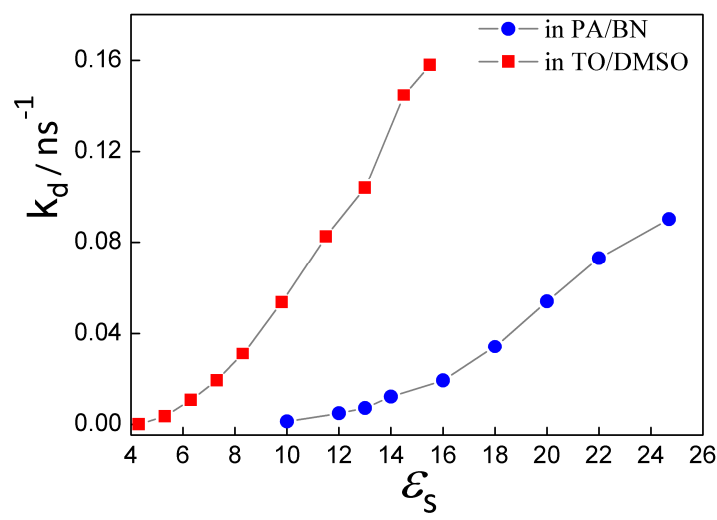

Fig. 8. The plot of exciplex dissociation rate constants, $k_{\mathrm{d}}$, as a function of solvent polarity of the DMAnt/DMA exciplexes. Mixtures of PA/BN (red squares) and TO/DMSO (blue circles) are used as micro-homogeneous and micro-heterogeneous binary solvents

\section{CONCLUSION}

By using the MFEs on the exciplexes of DMAnt/DMA system in micro-homogeneous and micro-heterogeneous binary solvents with systematically varying the static dielectric constants, $\varepsilon_{\mathrm{s}} \mathrm{s}$, we have been able to demonstrate that the MFE on the exciplex-forming organic acceptor/donor system is a powerful tool to investigate the preferential solvation effects. The onset and maximum MFEs of the exciplexes occur at smaller $\varepsilon_{\mathrm{s}}$ values in micro-heterogeneous solutions TO/DMSO in comparison to microhomogeneous mixtures PA/BN. The exciplexes dissociate into RIPs faster with increasing the mole fractions of polar components of $\mathrm{BN}$ or DMSO in mixtures. As a consequence, the exciplex lifetimes decrease in more polar solutions. All these results can be attributed to the preferential solvation of polar components (BN or DMSO) in mixtures. They form a polar cluster around solute molecules (RIPs or exciplexes) due to dipole-dipole interaction. In particular, with the presence of the high polar component DMSO in the polar cluster, the effects on the resulting observations are more significant.

\section{Trang 72}




\section{Ảnh hưởng của từ trường lên trạng thái kích thích của hệ cho/nhận hữu cơ: một công cụ hiệu quả để tìm hiểu quá trình dung môi hóa}

\section{- Hoàng Minh Hảo}

Trường Đại học Sư phạm Kỹ thuật, Thành phố Hồ Chí Minh

\section{- Phạm Thị Bích Vân}

Trường Đại học Nông Lâm, Thành phố Hồ Chí Minh

\section{TÓM TẮT}

Nhiều hẹ cho/nhận electron có thể hình thành các phức trao đổi điện tích ở trạng thái kích thích (exciplex) trong các phản úng trao đổi electron giũa chất nhận ở trạng thái kich thích và chất cho ở trạng thái nền. Exciplex có thể được phát hiện qua phổ huỳnh quang. Hơn nũa, sư phát huỳnh quang của exciplex bị ảnh huơong bởi tù̀ truờng ngoài. Trong nghiên cứu này, chúng tôi dựa vào ảnh hưởng của tù truòng ngoài lên exciplex của cặp cho/nhận electron $N, N$ dimethylaniline (chất cho)/ 9,10dimethylanthracene (chất nhận) trong các hệ hỗn hợp 02 dung môi đồng thể và dị thể để nghiên cúu các ảnh hưởng của quá trình dung môi hóa

Tù khóa: Exciplex, ảnh huởng tù truờng, trao đổi electron nhờ hấp thu năng lượng UV-Vis, cặp gốc ion

\section{REFERENCES}

[1]. M. Gordon, W.R. Ware, Eds., The Exciplex, Academic Press: New York, (1975).

[2]. H.M. Hoang, T. B. V. Pham, G. Grampp, D. R. Kattnig, Exciplexes versus loose ion pairs: How does the driving force impact the initial product ratio of photo-induced charge separation reactions?, J. Phys. Chem. Lett 5, 3188-3194 (2014).

[3]. D.R. Kattnig, A. Rosspeintner, G. Grampp, Magnetic field effects on exciplex-forming systems: The effect on the locally excited fluorophore and its dependence on free lên các chất tan trong dung dịch. Hằng số điện môi, $\varepsilon_{s}$, của hệ hỗn hợ 02 dung môi đồng thể propyl acetate (PA)/butyronitrile (BN) thay đổi trong khoảng 6,0 đến 24,6. Hồn hợp 02 dung môi di thể toluene (TO)/dimethylsulfoxide (DMSO) có hằng số điện môi thay đổi trong khoảng 4,3 đến 15,5. Trong môi truòng dị thể, các phân tử DMSO dung môi hóa ư thế các chất tan trong dung dịch bằng cách tạo một vi đám DMSO xung quanh chất tan. Tất cả nhũng ảnh hưởng của quá trình dung môi hóa được thể hiện qua sự thay đổi về tù truờng, thời gian tồn tại và động học của exciplex. energy, Phys, Chem. Chem. Phys, 13, 34463460 (2011).

[4]. S. Richert, G. Grampp, D.R. Kattnig, Timeresolved magnetic field effects distinguish loose ion pairs from exciplexes, J. Am. Chem. Soc 135, 15144-15152 (2013).

[5]. M.H. Hui, W.R. Ware, Exciplex photophysics. V. The kinetics of fluorescence quenching of anthracene by $N, \mathrm{~N}-$ dimethylaniline in cyclohexane, J. Am. Chem. Soc., 98, 4718-4727 (1976). 
[6]. P.A. Muller, C. Högemann, X. Allonas, P. Jacques, E. Vauthey, Deuterium isotope effect on the charge recombination dynamics of contact ion pairs formed by electron-transfer quenching in acetonitrile, Chem. Phys. Lett. 326, 326, 321-327 (2000).

[7]. I.R. Gould, R.H. Young, L.J. Mueller, S. Farid, Mechanisms of exciplex formation. Roles of super-exchange, solvent polarity, and driving force for electron transfer, J. Am. Chem. Soc.116, 8176-8187 (1994).

[8]. K. Pal, G. Grampp, D. R. Kattnig, Solvation dynamics of a radical ion pair in microheterogeneous binary solvents: A semiquantitative study utilizing MARY linebroadening experiments, ChemPhysChem 14, 3389-3399 (2013).

[9]. D.R. Kattnig, A. Rosspeintner, G. Grampp, Magnetic field effects on exciplex-forming systems: the effect on the locally excited fluorophore and its dependence on free energy, Angew. Chem. Int. Ed. 47, 960-962 (2008).

[10]. C.T. Rodgers, S.A. Norman, K. B. Henbest, C.R. Timmel, P.J. Hore, Determination of radical re-encounter probability distributions from magnetic field effects on reaction yields, J. Am. Chem. Soc. 129, 6746-6755 (2007).

[11]. S. Aich, S. Basu, Magnetic field effect: A tool for identification of spin state in a photoinduced electron-transfer reaction, $J$. Phys. Chem. A 102, 722-729 (1998).

[12]. M. Justinek, G. Grampp, S. Landgraf, P.J. Hore, N.N. Lukzen, Electron self-exchange kinetics determined by MARY spectroscopy: theory and experiment, J. Am. Chem. Soc. 126, 5635-5646 (2004).

[13]. R. Kaptein, L. Oosterhoff, Chemically induced dynamic nuclear polarization II, $J$. Chem. Phys. Lett. 4, 195-197 (1969).

[14]. G. Closs, Mechanism explaining nuclear spin polarizations in radical combination reactions, J. Am. Chem. Soc. 91, 4552-4554 (1969).
[15]. U.E. Steiner and T. Ulrich, Magnetic field effects in chemical kinetics and related phenomena, Chem. Re. 89, 51-147 (1989).

[16]. K.M. Salikhov, I.N. Molin, A.L. Buchachenko, Eds., Spin polarization and magnetic effects in radical reactions, Elsevier ; Akadémiai Kiadó, Amsterdam ; New York: Budapest, Hungary, (1984).

[17]. H. Hayashi, Introduction to dynamic spin chemistry: magnetic field effects on chemical and biochemical reactions, World Scientific, River Edge, N.J, (2004).

[18]. G.J. Kavarnos, Fundamentals of photoinduced electron transfer, VCH Publishers, New York, NY, (1993).

[19]. R.A. Marcus, On the theory of oxidation-reduction reactions involving electron transfer I, J. Chem. Phys. 24, 966-978 (1956).

[20]. R.A. Marcus, N. Sutin, Electron transfers in chemistry and biology, Biochim. Biophys. Acta. Rev. Bioenerg. 811, 265-322 (1985).

[21]. A. Ali, A.K. Nain, D. Chand, R. Ahmad. R, Viscosities and refractive indices of binary mixtures of dimethylsulfoxide with some aromatic hydrocarbons at different temperature: An experimental and theoretical study, J. Chin. Chem. Soc. 53, 531-543 (2006).

[22]. D.R. Kattnig, A. Rosspeintner, G. Grampp, Magnetic field effects on exciplex-forming systems: The effect on the locally excited fluorophore and its dependence on free energy Phys. Chem. Chem. Phys. 13, 3446-3460 (2011).

[23]. M.G. Kuzmin, I.V. Soboleva, E.V. Dolotova, The behavior of exciplex decay processes and interplay of radiationless transition and preliminary reorganization mechanisms of electron transfer in loose and tight pairs of reactants, J. Phys. Chem. A 111, 206-215 (2007).

[24]. P. Suppan, Local polarity of solvent mixtures in the field of electronically excited molecules and exciplexes, J. Chem. Soc. Faraday Trans.

Trang 74 
1 Phys. Chem. Condens. Phases 83, 495-509 (1987).

[25]. D.N. Nath, M. Chowdhury, Effect of environment on the magnetic field modulation of exciplex luminescence, Chem. Phys. Lett. 109, 13-17 (1984).

[26]. N.K. Petrov, V.N. Borisenko, A.V. Starostin M.V. Al'fimov, Polar molecular clusters produced upon photoinduced electron transfer in an intermolecular exciplex in binary solvents, J. Phys. Chem. 96, 2901-2903 (1992).

[27]. N.K. Petrov, A fluorescence spectroscopy study of preferential solvation in binary solvents, High Energy Chem. 40, 22-34 (2006).
[28]. N.K. Petrov, A. Wiessner, H. Staerk, A simple kinetic model of preferential solvation in binary mixtures, Chem. Phys. Lett. 349, 517-520 (2001).

[29]. P. Suppan, Invited review solvatochromic shifts: The influence of the medium on the energy of electronic states, J. Photochem. Photobiol. A, 50, 293-330 (1990).

[30]. I.R. Gould, S. Farid, Fluorescence of excited charge-transfer complexes and absolute dynamics of radical-ion pairs in acetonitrile, J. Phys. Chem. 96, 7635-7640 (1992).

[31]. M.V. Basilevsky, A.V. Odinokov, E.A. Nikitina, N.C. Petrov, The dielectric continuum solvent model adapted for treating preferential solvation effects, J. Electroanal. Chem. 660, 339-346 (2011). 